\title{
Prevention of exertional lower body musculoskeletal injury in tactical populations: protocol for a systematic review and planned meta-analysis of prospective studies from 1955 to 2018
}

Shawn D. Flanagan ${ }^{1 *}$ (D, Aaron M. Sinnott ${ }^{1}$, Kellen T. Krajewski ${ }^{1}$, Caleb D. Johnson ${ }^{1}$, Shawn R. Eagle ${ }^{1}$, Alice D. LaGoy ${ }^{1}$, Meaghan E. Beckner ${ }^{1}$, Anne Z. Beethe', Rose Turner², Mita Lovalekar ${ }^{1}$, Courtenay Dunn-Lewis ${ }^{1,3}$, Chris Connaboy ${ }^{1}$ and Bradley C. Nindl ${ }^{1}$

\begin{abstract}
Background: Exertional lower body musculoskeletal injuries (ELBI) cost billions of dollars and compromise the readiness and job performance of military service and public safety workers (i.e., tactical populations). The prevalence and burden of such injuries underscores the importance of prevention efforts during activities necessary to sustain core occupational competencies. Attempts to synthesize prevention techniques specific to tactical populations have provided limited insight on the comparative efficacy of interventions that do not modify physical training practices. There is also a need to assess the influence of sex, exposure, injury classification scheme, and study design. Thus, the primary purpose of the systematic review and planned meta-analysis detailed in this protocol is to evaluate the comparative efficacy of ELBI prevention strategies in tactical populations.

Methods: A systematic search strategy will be implemented in MEDLINE, EMBASE, Cochrane, and CINAHL. A multi-tiered process will be used to capture randomized controlled trials and prospective cohort studies that directly assess the prevention of ELBI in tactical population(s). Extracted data will be used to compare prevention strategies and assess the influence of heterogeneity related to occupation, sex, exposure, injury characteristics, and study quality. In addition, individual risk of bias, meta-bias, and the quality of the body of evidence will be rigorously tested.

Discussion: This systematic review and planned meta-analysis will comprehensively evaluate ELBI mitigation strategies in tactical populations, elucidate factors that influence responses to treatment, and assess the overall quality of the body of research. Results of this work will guide the prioritization of ELBI prevention strategies and direct future research efforts, with direct relevance to tactical, health and rehabilitation science, and human performance optimization stakeholders.

(Continued on next page)
\end{abstract}

\footnotetext{
* Correspondence: sdf.29@pitt.edu

${ }^{1}$ Neuromuscular Research Laboratory and Warrior Human Performance

Research Center, Department of Sports Medicine and Nutrition, School of

Health and Rehabilitation Sciences, University of Pittsburgh, Pittsburgh, PA,

USA

Full list of author information is available at the end of the article
}

(c) The Author(s). 2018 Open Access This article is distributed under the terms of the Creative Commons Attribution 4.0 International License (http://creativecommons.org/licenses/by/4.0/), which permits unrestricted use, distribution, and reproduction in any medium, provided you give appropriate credit to the original author(s) and the source, provide a link to the Creative Commons license, and indicate if changes were made. The Creative Commons Public Domain Dedication waiver (http://creativecommons.org/publicdomain/zero/1.0/) applies to the data made available in this article, unless otherwise stated. 
(Continued from previous page)

Systematic review registration: The systematic review protocol was registered with the International Prospective Register of Systematic Reviews (PROSPERO) on 3 Jan 2018 (registration number CRD42018081799).

Keywords: Biomechanics, Epidemiology, Exercise, Prevention, Knee, Overuse, Performance, Rehabilitation, Risk factors, Training

\section{Background}

The prevention of musculoskeletal injury (MSI) is central to efforts to improve the readiness, performance, and long-term health of tactical populations (i.e., military, police, firefighters, and emergency medical services (EMS)) [1-4]. In the US military, MSI is responsible for nearly $75 \%$ of limited duty cases and costs billions of dollars annually [5-9]. Physical exertion associated with training, occupational tasks, and recreation is the primary cause of acute hospitalization $[10,11]$, and $40 \%$ of such injuries occur in the lower body. The incidence of ELBI is similarly pronounced in police, firefighters, and EMS [1216]. The burden of ELBI in tactical populations underscores the importance of injury prevention.

Reviews on ELBI prevention typically delimit injury assessment to a specific anatomic structure (e.g., groin, knee, ankle) [17-24] or classification (e.g., stress fractures, osteoarthritis, strains, sprains) [17, 20, 25-29]. The systemic effects of most interventions (e.g., additional or modified physical activity, educational programs, footwear modification) and integrative nature of structures within the lower kinetic chain justify a more generalized analysis of interventions and ELBI outcomes [30]. Additionally, a collective approach to the comparison of ELBI prevention strategies may improve translation to relevant stakeholders.

Despite growing evidence to support prevention strategies specific to tactical populations [8, 9, 31-38], current practices largely reflect information obtained from high school and college athletes [18, 19, 21, 23, 24, 39-43]. Most reviews emphasize subpopulations such as American football $[27,28,41]$, soccer $[19,40,44]$, or basketball $[18,20,23,24]$. While relevant, the demands placed on tactical populations differ profoundly from athletics in terms of occupational tasks, exposure patterns, and underlying behavioral and environmental factors. In contrast to tactical populations for example, athletic physical exertion is generally defined, planned, and conducted in relatively well-controlled environments with predictable recovery periods.

A recent systematic review of military ELBI prevention identified six overarching strategies: (1) conditioning, (2) footwear modifications, (3) bracing, (4) physical activity volume, (5) physical fitness, and (6) leadership/supervision/awareness [30]. The majority of studies (26/43) sought to improve physical conditioning, but sex-specific responses were evident [30]. Less than half $(19 / 44)$ of the interventions were specific to the military, and none examined public safety workers. A more comprehensive search strategy would likely improve the breadth of literature capture, especially in the case of novel or unusual interventions and less frequently studied tactical populations [45]. Furthermore, the stratification of aggregated data would improve analytic power and allow for normalized comparisons based on sex, exposure level, and injury classification [46].

In this systematic review and planned meta-analysis, we will identify and evaluate the collective prospective evidence on ELBI prevention in to tactical populations. The comparative efficacy of prevention strategies will be examined for ELBI overall, with additional subanalyses of participant-, exposure-, and injury-specific responses determined by the extant literature base. The meta-analysis will use internationally recognized standards to assess individual and overall risk of bias, in addition to the quality of the body of evidence. Aggregate- and group-level data will be used to quantify the influence of study, participant, and injury characteristics. The findings of this review are intended to establish efficacy and support the prioritization of ELBI prevention strategies.

\section{Objectives}

The primary objective of this systematic review and planned meta-analysis is to evaluate interventions and prospective observations for the prevention of ELBI in tactical populations. The proposed systematic review will address the following topics:

1. Comparative efficacy of intervention strategies to reduce ELBI in tactical populations.

2. Moderating influence of participant, study, and injury characteristics

\section{Methods \\ Eligibility criteria}

Studies will be selected based on the following criteria for design, participants, interventions, comparators, outcomes, and other study traits. 


\section{Study designs}

To evaluate the comparative preventive efficacy of interventions for ELBI, controlled trials and prospective observational studies will be included. Acceptable study designs include parallel (between-group), cross-over (within-group), cluster, factorial trials, and non-randomized trials or prospective observational studies with direct between-group comparisons. Single-arm studies without direct comparisons will be excluded (e.g., benchmarking, simulated comparisons). Retrospective studies, cross-sectional studies, case reports and series, ideas, opinions, editorials, animal research, and in vitro research will be excluded.

\section{Participants}

Studies on adults aged 18 years or older will be included. Participants must be active military service members or public safety workers (including police, firefighters, and EMS). International military members that meet the national age requirement will be included. Studies of the target populations after retirement will be excluded.

\section{Interventions}

Qualifying studies will have the primary aim of preventing or mitigating ELBI in non-injured tactical population(s). Interventions targeting overall MSI risk will be included when lower body injury outcomes are presented or made available upon request. Non-specific behavioral, educational, or policy interventions will be included. Examples include new conditioning practices; modification or elimination of detrimental behaviors; education programs; policies that mandate, restrict, or otherwise influence occupational tasks; and external devices that prevent ELBI by providing protection or information.

Terminology to define injury is provided by the International Classification of Diseases (ICD-9-M) [47, 48] and National Institute for Occupational Safety and Health (NIOSH) [1]. Qualifying injuries will include fractures, derangements, dislocations, sprains, strains, and other injuries or disorders of the muscles, nerves, tendons, joints, or cartilage of the lower limbs. Such injuries must be caused, precipitated, or exacerbated by sudden or prolonged exertion involving movement repetition, force, vibration, or adverse biomechanics. Injuries resulting from falls, motor vehicle accidents, violence, and war will be excluded.

\section{Comparators}

Controls will include participants who receive placebo or "standard of care" treatment. The anticipated standard of care includes normal physical training activities without significant modification. Several potential comparators are relevant to the prevention of ELBI. Prominent examples are listed below but others will be considered on a case-by-case basis depending on the literature base.

1. Modification or elimination of practices that cause injury versus maintenance

2. High dose of intervention versus lower dose(s) of intervention

3. Interventions that influence conduct or access to activities associated with injury

4. Non-specific or multi-faceted behavioral, educational, or policy interventions versus no intervention or similar intervention(s) at a reduced dose

\section{Outcomes}

Outcomes and their definitions will be collected as reported in individual studies. Binary injury incidence data will be extracted to represent ELBI outcomes. Anticipated outcome measures include incidence, odds ratios, risk ratios, hazard ratios, and likelihood ratios. Outcomes may be derived from self-report, medical records, behavioral performance, medical imaging, physiological measurements, and biological specimens. Studies that do not report injury incidence will be excluded. Outcome measurements specific to ELBI will be extracted. Composite and upper body MSI will not be included, and studies that do not report or provide lower body-specific data will be excluded. If ELBI is subdivided by structure, tissue, category, or other factors, all levels of data will be extracted and pooled depending on injury classification.

\section{Timing}

Studies with a minimum surveillance period of 3 months will be prioritized. Due to many studies being conducted with recruits during basic training, to account for branches with shorter training periods $[49,50]$, studies with surveillance durations of at least 2 months will be considered if otherwise acceptable and of sufficient quality as determined by the review team.

\section{Setting}

Study setting is unrestricted.

\section{Language}

Included articles will be reported in English. When applicable, studies involving predominantly non-English speaking populations will be included.

\section{Other review eligibility criteria}

Study inclusion will not be restricted by geographic region. Inclusion will be limited to original research articles published in peer-reviewed journals. Abstracts, unpublished data, commentaries, letters, and conference proceedings will be screened. Data from 1955 to 2018 will be evaluated for systematic variation of effect 
estimates associated with publication age and normalized or sub-grouped as necessary.

\section{Information sources}

MEDLINE, EMBASE, Cochrane, and CINAHL electronic databases will be searched. We will also search the reference lists of included publications, relevant reviews, and gray literature. Article listings in the top five journals of included studies will be searched from 2018 to 2003. The final reference list will be circulated among the review team and external experts identified by the team. The search strategy will meet IOM Standards for Systematic Reviews [51] and guidelines set forth in the Cochrane Handbook for Systematic Reviews of Interventions.

\section{Search strategy}

The search strategy will use medical subject headings $(\mathrm{MeSH})$ and text words that identify the target populations, injuries and structures, exposures and practices, and analysis features relevant to injury prediction. Searches will be limited to original human research articles published in peer-reviewed journals in English. Searches will not be limited by publication year or study design. The MEDLINE search strategy will be developed by a health sciences Librarian with expertise in systematic review searches (RT) in collaboration with the project team and reviewed by an additional Librarian (see Additional file 1 for search strategy). The MEDLINE search strategy will be adapted for use with EMBASE, Cochrane, and CINAHL databases. The electronic database search will be updated and re-run before the final analysis to capture new studies and confirm retrieval of a high proportion of eligible studies. PROSPERO will be searched for ongoing and completed reviews at the beginning and end of the review process. Recently completed systematic reviews will be searched for new articles.

\section{Study records}

\section{Data management}

Citation abstracts and full-text articles captured during the literature search will be uploaded into Distiller Systematic Review (DSR) software for screening. Before DSR upload, duplicate search results will be removed using Endnote reference management software. When multiple reports on a study are identified, the study team will assess the consistency of reported study design, sample size, outcome(s), and statistical test(s). All relevant original information will be extracted and collated. In the event of multiple versions, the initial version will be retained. The inclusion and exclusion criteria will be developed into a series of forms for article screening (see Additional file 2 for screening forms). The forms will be tested and refined before formal screening. New members of the team will be trained on the content area and DSR software before participation.

\section{Selection process}

Titles of studies retrieved from the search will be independently screened by two reviewers for relevance to the prediction of ELBI. Reviewers will be blind to study author(s), journal title, and institution. For level 2 screening, abstracts will be reviewed for requisite study outcomes. Level 3 screening will confirm the eligibility of the participant population. Following the completion of level three screening, a quality control check will be conducted on all relevant articles by senior review team members (MB, KK, AL, AS) before the commencement of full-text screening. After the quality control check, if the inclusion criteria are met or inconclusive, the full text will be obtained for level four screening. Any article marked for removal will require agreement from three independent senior review members. When questions about study eligibility persist, study authors will be contacted for additional information. If the study author does not respond to contact for additional information or the response is deemed inadequate, the study will be screened and reason(s) noted. Disagreements about inclusion will be resolved through discussion or final review by a third author. Reason(s) for exclusion will be recorded and reported. Inter-rater agreement will be analyzed after the completion of three selection process procedures: (1) initial assessment test, (2) refinement, and (3) formal screening process.

\section{Data collection process}

Data will be extracted in duplicate by two independent reviewers using standardized forms in DSR. To improve consistency, data extraction forms will be pre-piloted in conjunction with the selection forms (see Additional file 3 for data extraction forms). Disagreements will be resolved by a third reviewer (SF, CC, CD, or ML). When data from primary studies are not presented in a usable format, the study authors will be contacted and asked to provide the missing data. We will attempt to contact primary authors up to three times by email or phone. The original study authors will also be contacted to confirm the accuracy of the final extracted data and resolve remaining uncertainties. In the event of uncertainty or missing data failure to respond, comply, or follow-up will result in study exclusion. When multiple reports of a single study are identified non-duplicated information will be collated. Otherwise, data from the initial report will be included with the exclusion of duplicates noted.

\section{Data items}

Extracted data will include study characteristics (study setting and design, sample size, duration of follow-up, 
type of control, methods, intervention type, measurement techniques, time points, indicators of acceptability, side effects), participant and exposure characteristics (occupation, duration of participation, demographic, anthropometric, biological, workload, history, fitness), injury characteristics (injury definition, reporting method, location, and subtype,), author interpretation(s) of findings, suggested mechanisms of action, potential confounds, information for the assessment of risk of bias, and information consistent with the Template for Intervention Description and Replication (TIDieR) [52].

Outcomes specific to anatomic locations (e.g., knee), structures (e.g., anterior cruciate ligament), and disorders (e.g., sprain) will be collected for further analysis or aggregation. In the health and rehabilitation science literature, MSI is often classified as non-traumatic (overuse) or traumatic (acute). If descriptions are consistent across studies, injuries will be sub-typed accordingly. For cross-over trials, data from the first baseline period will be extracted. Measures of central tendency and variability will be extracted from figures when necessary using plot digitization software. If effect sizes cannot be calculated, study authors will be contacted for additional information.

\section{Outcomes and prioritization \\ Primary outcome}

The primary outcome is ELBI incidence. Risk ratios will be calculated from the total number of participants at each measurement time point.

\section{Secondary outcomes}

1. Limited duty days prevented by the intervention

2. Cost reduction

3. Measures of acceptability, efficacy, and tolerability

(a) Attrition for any reason: a measure of overall treatment acceptability

(b) Attrition due to inefficacy of treatment: a global measure of efficacy

(c) Attrition due to adverse events: a global measure of tolerability

4. Side effects

(a) Number of participants who experienced one or more side effect

\section{Risk of bias}

Two blinded reviewers will independently assess risk of bias for each included study. Disagreement between the reviewers will be resolved after discussion or final decision by a third reviewer (SF, CC, CD, or ML). To assess the risk of study bias and overall study quality, the following factors will be considered: sample definition and representation, adequate randomization, adequate allocation concealment, blinding, completeness of outcome data, and selective outcome reporting. For each domain, descriptions provided in the study will be collected as reported and scored using the risk of bias (RoB 2.0) for randomized controlled trials and the Risk of Bias In Non-randomized Studies - of Interventions (RoBINS-I) for prospective cohort studies [53]. When insufficient information is provided, the original study author(s) will be contacted for clarification. The risk of bias will be summarized graphically across studies. The synthesis will include a subgroup analysis to examine the influence of study quality on the overall findings of the review. Low-quality studies may be excluded from the final analysis.

\section{Data synthesis}

Under the assumption of sufficient homogeneity, quantitative analysis of aggregate participant data will be conducted. The planned analytical approach will include a narrative synthesis of the findings from the included studies, structured around prevention interventions and participant, exposure, and study characteristics. If a study incorporates more than two relevant treatment groups, information from each group will be summarized with further analysis of combined data as appropriate (e.g., two levels of a treatment class combined for comparison against another treatment class). Original study authors will be contacted when there are missing data. Binary ELBI outcomes will be expressed as estimates of relative risk using risk ratios (lnRR) with 95\% confidence intervals (CI).

The results of included studies will be pooled and analyzed using stratified random effects meta-analysis (RevMAN v5.3, The Cochrane Collaboration) [54, 55]. Subgroup and meta-regression (Stata, StataCorp) analyses will be used to determine whether treatment estimates are influenced by potential effect modifiers such as study characteristics and participant characteristics (see "Subgroup Analysis" section below). Statistical heterogeneity will be determined with chi-square $\left(\chi^{2}\right)$ and $I^{2}(0-100 \%)$ statistics, with $X^{2} p>0.10$ and $I^{2}>50 \%$ indicative of substantial heterogeneity [56]. Betweenstudy variance $\left(\tau^{2}\right)$ will be assessed in relation to effect size estimates. In the event of substantial heterogeneity [57], sensitivity analysis will be conducted as indicated by subgroup comparisons, RoB 2.0, and ROBINS-I checklists.

The presentation of results will be ordered by objective. Important comparisons and subgroup analyses will be presented based on the availability of data. Results will be presented in narrative text, tables, and figures. Depending on the results of sensitivity and subgroup analyses, studies with a high risk of bias may be excluded from the final meta-analysis. 


\section{Subgroup analysis}

If the necessary data are available, subgroup analyses will be used to investigate sources of between-study heterogeneity and the robustness of the meta-analysis. Comparisons will be considered on a case-by-case basis depending on the literature base with the maximal feasible amount of data extracted for the following factors:

1. Participant characteristics (e.g., sex, age, occupation)

2. Injury location, structure, class (e.g., knee, patellar tendon, tendinopathy)

3. Injury subtype (acute vs. non-traumatic)

4. Intervention type (e.g., educational program vs. targeted training)

5. Surveillance period (e.g., 3 months vs. 1 year)

6. Study-specific factors

(a) Study design (e.g., randomized vs. nonrandomized)

(b) Sample size

(c) Overall study quality

(d) Risk of bias (e.g., all studies versus low bias studies only)

(e) Publication age

\section{Meta-bias}

The possibility of publication and outcome reporting bias will be explored with funnel plots and the RoB 2.0 and ROBINS-I checklists. Small sample bias will be assessed by comparing fixed effects estimates with random effects models. Furthermore, continuous and dichotomous risk factors will be compared in RevMan and presented as interpretable rates (e.g., odds/risk/hazard ratio). Results may be used to re-weigh studies or for subgroup analysis. The analysis and reporting techniques used in this review will comply with guidelines provided by the Measurement Tool to Assess Systematic Reviews (AMSTAR-2) [58]. For information on compliance with PRIMSA-P review guidelines, see Additional file 4.

\section{Confidence in cumulative estimate}

The overall quality of the body of evidence will be determined with the Grading of Recommendations Assessment, Development, and Evaluation (GRADE) approach [59]. Studies excluded from the meta-analysis will be excluded from the GRADE assessment. GRADE results will be used to inform conclusions on the overall strength of predictors of ELBI in military and public safety populations.

\section{Discussion}

Exertional lower body musculoskeletal injuries negatively impact the health, performance, and readiness of military and public safety populations. There is a need to quantitatively synthesize and evaluate the comparative efficacy of strategies to prevent such injuries. In addition to a comprehensive search strategy, this systematic review and planned meta-analysis adds to the extant literature base in its use of rigorous multi-level screening processes and quantitative consideration of study bias, age, and quality. Prevention strategies with higher overall efficacy will be identified, with further analysis to examine the influence of participant-, injury-, and study-specific characteristics. The results of this review will provide a robust and comprehensive resource to guide the prioritization of ELBI prevention strategies and direct future research efforts.

\section{Additional files}

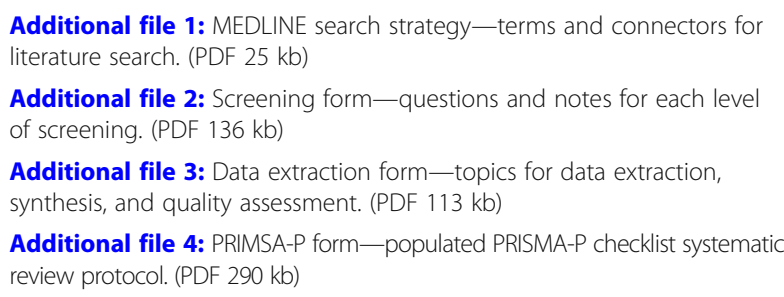

Additional file 4: PRIMSA-P form—-populated PRISMA-P checklist systematic review protocol. (PDF $290 \mathrm{~kb}$ )

\begin{abstract}
Abbreviations
AMSTAR-2: Measurement Tool to Assess Systematic Reviews; Cl: Confidence intervals; CINAHL: Cumulative Index to Nursing and Allied Health Literature; DSR: Distiller Systematic Review; ELBI: Exertional lower body injury; EMBASE: Excerpta Medica Database; EMS: Emergency medical service; GRADE: Grading of Recommendations Assessment, Development, and Evaluation; ICD: International Classification of Diseases; IOM: Institute of Medicine; MEDLINE: US National Library of Medicine bibliographic database; MeSH: Medical subject headings; MSI: Musculoskeletal injury; NIOSH: National Institute for Occupational Safety and Health; PRISMA: Preferred Reporting Items for Systematic Reviews and Meta-Analyses; PROSPERO: International prospective register of systematic reviews; RCT: Randomized controlled trial; RoB-2.0: Revised tool for risk of bias in randomized trials; ROBINS-I: Risk of Bias In Non-Randomized Studies - of Interventions; RR: Risk ratio;

TIDieR: Template for Intervention Description and Replication
\end{abstract}

\section{Acknowledgements}

The authors thank Camille Johnson, Alexis Faunce, Brandon Sciavolino, Madeline Wells, Audrey Bentley, Sadhana Sridhar, Megan Magarity, and Daniel Biery for their assistance in level 1-3 screening and providing critical feedback for the development and refinement of the screening and extraction forms.

\section{Support}

The Neuromuscular Research Laboratory at the University of Pittsburgh sponsors and retains full control of the data. The authors maintain sole responsibility for protocol development, review conduct, data analysis and interpretation, and dissemination. No funding has been received for this study.

\section{Amendments}

If the protocol is amended, the date, description, and rationale of change(s) will be provided in this section. Changes will not be incorporated into the protocol. SF will be responsible for the approval, documentation, and implementation of amendment(s).

\section{Authors' contributions}

$\mathrm{SF}$ is the guarantor of the study. SF, CC, CD, KK, AS, CJ, AB, SE, MB, AL, and $\mathrm{BN}$ drafted the manuscript. All authors contributed to the development of the selection criteria, bias assessment strategy, and data extraction criteria. RT developed the search strategy. ML provided statistical expertise. CC and BN provided expertise on lower body injury in tactical populations. All authors read, provided feedback, and approved the final manuscript. 


\section{Competing interests}

The authors declare that they have no competing interests.

\section{Publisher's Note}

Springer Nature remains neutral with regard to jurisdictional claims in published maps and institutional affiliations.

\section{Author details}

'Neuromuscular Research Laboratory and Warrior Human Performance Research Center, Department of Sports Medicine and Nutrition, School of Health and Rehabilitation Sciences, University of Pittsburgh, Pittsburgh, PA, USA. ${ }^{2}$ Health Sciences Library System, University of Pittsburgh, Pittsburgh, PA, USA. ${ }^{3}$ Department of Health and Physical Activity, School of Education, University of Pittsburgh, Pittsburgh, PA, USA.

\section{Received: 15 December 2017 Accepted: 13 April 2018}

\section{Published online: 05 May 2018}

\section{References}

1. Health NIfOSa. Musculoskeletal health program: centers for disease control and prevention. 2017. Available from: https://www.cdc.gov/niosh/programs/msd/. [cited 2017 May 20].

2. Maguire BJ, Smith S. Injuries and fatalities among emergency medical technicians and paramedics in the United States. Prehosp Disaster Med. 2013;28(4):376-382. Epub 2013/05/11. https://doi.org/10.1017/ S1049023X13003555. PubMed PMID: 23659321.

3. Bulzacchelli MT, Sulsky SI, Rodriguez-Monguio R, Karlsson LH, Hill MO. Injury during U.S. army basic combat training: a systematic review of risk factor studies. Am J Prev Med. 2014;47(6):813-822. Epub 2014/12/03. https://doi. org/10.1016/j.amepre.2014.08.008. PubMed PMID: 25455122

4. Gray SE, Collie A. The nature and burden of occupational injury among first responder occupations: a retrospective cohort study in Australian workers. Injury. 2017 48(11):2470-2477. Epub 2017/10/02. https://doi.org/10.1016/j. injury.2017.09.019. PubMed PMID: 28964511.

5. Hauret KG, Jones BH, Bullock SH, Canham-Chervak M, Canada S. Musculoskeletal injuries description of an under-recognized injury problem among military personnel. Am J Prev Med. 2010;38(1 Suppl):S61-S70. Epub 2010/02/13. https://doi.org/10.1016/j.amepre.2009.10.021. PubMed PMID: 20117601

6. Jones BH, Canham-Chervak M, Canada S, Mitchener TA, Moore S. Medical surveillance of injuries in the U.S. military descriptive epidemiology and recommendations for improvement. Am J Prev Med. 2010;38(1 Suppl):S42S60. Epub 2010/02/13. https://doi.org/10.1016/j.amepre.2009.10.014. PubMed PMID: 20117600.

7. Jones BH, Knapik JJ. Physical training and exercise-related injuries. Surveillance, research and injury prevention in military populations. Sports Med. 1999;27(2):111-25. Epub 1999/03/26. PubMed PMID: 10091275

8. Nindl BC, Williams TJ, Deuster PA, Butler NL, Jones BH. Strategies for optimizing military physical readiness and preventing musculoskeletal injuries in the 21st century. US Army Med Dep J. 2013;Oct-Dec:5-23.

9. Ruscio BA, Jones BH, Bullock SH, Burnham BR, Canham-Chervak M, Rennix CP, Wells TS, Smith JW. A process to identify military injury prevention priorities based on injury type and limited duty days. Am J Prev Med. 2010; 38(1 Suppl):S19-S33. Epub 2010/02/13. https://doi.org/10.1016/j.amepre. 2009.10.004. PubMed PMID: 20117593.

10. Jones BH, Hauschild VD. Physical training, fitness, and injuries: lessons learned from military studies. J Strength Cond Res. 2015;29(Suppl 11):S5764.

11. Canham-Chervak M, Hooper TI, Brennan FH, Craig SC, Girasek DC, Schaefer RA, Barbour G, Yew KS, Jones BH. A systematic process to prioritize prevention activities sustaining progress toward the reduction of military injuries. Am J Prev Med. 2010;38(1):S11-S8. https://doi.org/10.1016/j.amepre. 2009.10.003. PubMed PMID: WOS:000273413900002.

12. NIST. The economic consequences of firefighter injuries and their prevention: final report. 2004.

13. Haynes HJM, J. L. U.S. Firefighter Injuries - 2015. National Fire Protection Association, 2016 October 2016. Report No.

14. Firefighter. IAo. 1998 death and injury survey Washington, DC. Washington, DC: International Association of Firefighters; 1999.

15. Molis HJGHaJL. NFPA's "U.S. firefighter injuries--2016". 2017.
16. Owens BCK. The burden of musculoskeletal injuries in the military. New York: Springer; 2016.

17. Esteve E, Rathleff MS, Bagur-Calafat C, Urrutia G, Thorborg K. Prevention of groin injuries in sports: a systematic review with meta-analysis of randomised controlled trials. Br J Sports Med. 2015;49(12):8. https://doi.org/ 10.1136/bjsports-2014-094162. PubMed PMID: WOS:000355552000008

18. ter Stege MHP, Dallinga JM, Benjaminse A, Lemmink K. Effect of interventions on potential, modifiable risk factors for knee injury in team ball sports: a systematic review. Sports Med. 2014;44(10):1403-26. https:// doi.org/10.1007/s40279-014-0216-4. PubMed PMID: WOS:000344974200007

19. Al Attar WSA, Soomro N, Pappas E, Sinclair PJ, Sanders RH. How effective are F-MARC injury prevention programs for soccer players? A systematic review and meta-analysis. Sports Med. 2016:46(2):205-17. https://doi.org/10.1007/ s40279-015-0404-x. PubMed PMID: WOS:000378134500005

20. Taylor JB, Waxman JP, Richter SJ, Shultz SJ. Evaluation of the effectiveness of anterior cruciate ligament injury prevention programme training components: a systematic review and meta-analysis. Br J Sports Med. 2015; 49(2):79-U29. https://doi.org/10.1136/bjsports-2013-092358. PubMed PMID: WOS:000347105900004

21. Yeung EW, Yeung SS. A systematic review of interventions to prevent lower limb soft tissue running injuries. Br J Sports Med. 2001;35(6):383-9. https://doi.org/10.1136/bjsm.35.6.383. PubMed PMID: WOS:000172605700004

22. Kalirathinam D, Ismail MS, Singh TSP, Saha S, Hashim HA. Does neuromuscular exercise training improve proprioception in ankle lateral ligament injury among athletes? Systematic review and meta-analysis. Sci Med. 2017;27(1):8. https://doi.org/10.15448/1980-6108.2017.1.25082. PubMed PMID: WOS:000398105600004

23. Brachman A, Kamieniarz A, Michalska J, Pawlowski M, Slomka KJ, Juras G. Balance training programs in athletes-a systematic review. J Hum Kinet. 2017:58(1):45-64. https://doi.org/10.1515/hukin-2017-0088. PubMed PMID: WOS:000407005600005

24. Taylor JB, Ford KR, Nguyen AD, Terry LN, Hegedus EJ. Prevention of lower extremity injuries in basketball: a systematic review and meta-analysis. Sports Health. 2015;7(5):392-8. https://doi.org/10.1177/1941738115593441. PubMed PMID: WOS:000214894000002

25. Bonanno DR, Landorf KB, Munteanu SE, Murley GS, Menz HB. Effectiveness of foot orthoses and shock-absorbing insoles for the prevention of injury: a systematic review and meta-analysis. Br J Sports Med. 2017;51(2):86-+. https:// doi.org/10.1136/bjsports-2016-096671. PubMed PMID: WOS:000391443300004

26. Jones BH, Thacker SB, Gilchrist J, Kimsey JCD, Sosin DM. Prevention of lower extremity stress fractures in athletes and soldiers: a systematic review. Epidemiol Rev. 2002;24(2):228-47. https://doi.org/10.1093/epirev/mxf011.

27. Driban JB, Hootman JM, Sitler MR, Harris KP, Cattano NM. Is participation in certain sports associated with knee osteoarthritis? A systematic review. J Athl Train. 2017;52(6):497-506. https://doi.org/10.4085/1062-6050-50.2.08 PubMed PMID: WOS:000404154700003

28. Goldman EF, Jones DE. Interventions for preventing hamstring injuries: a systematic review. Physiotherapy. 2011;97(2):91-9. https://doi.org/10.1016/j. physio.2010.11.011. PubMed PMID: WOS:000289547300001

29. Lin CWC, Uegaki K, Coupe VMH, Kerkhoffs GM, van Tulder MW. Economic evaluations of diagnostic tests, treatment and prevention for lateral ankle sprains: a systematic review. Br J Sports Med. 2013;47(18):1144-+. https://doi. org/10.1136/bjsports-2012-090319. PubMed PMID: WOS:000327249500004

30. Wardle SL, Greeves JP. Mitigating the risk of musculoskeletal injury: a systematic review of the most effective injury prevention strategies for military personnel. J Sci Med Sport. 2017;20(Suppl 4):S3-S10. https://doi.org/ 10.1016/j.jsams.2017.09.014

31. Anderson MK, Grier T, Canham-Chervak M, Bushman TT, Jones BH. Physical training, smoking, and injury during deployment: a comparison of men and women in the US Army. US Army Med De J. 2015;Apr-Jun:42-8. PubMed PMID: 26101905.

32. Anderson MK, Grier T, Dada EO, Canham-Chervak M, Jones BH. The role of gender and physical performance on injuries: an Army study. Am J Prev Med. 2017;52(5):e131-e1e8. Epub 2016/12/26. https://doi.org/10.1016/j. amepre.2016.11.012. PubMed PMID: 28012810.

33. Epstein $Y$, Fleischmann C, Yanovich R, Heled Y. Physiological and medical aspects that put women soldiers at increased risk for overuse injuries. J Strength Cond Res. 2015;29(Suppl 11):S107-10. https://doi.org/10.1519/JSC. 0000000000001079. PubMed PMID: 26506172

34. Gilchrist J, Jones BH, Sleet DA, Kimsey CD, CDC, Exercise-related injuries among women: strategies for prevention from civilian and military studies. 
MMWR Recomm Rep. 2000;49(RR-2):15-33. Epub 2004/12/08. PubMed PMID: 15580730.

35. Kaufman KR, Brodine S, Shaffer R. Military training-related injuries: surveillance, research, and prevention. Am J Prev Med, 2000. 18(3 Suppl):5463. Epub 2000/03/29. PubMed PMID: 10736541

36. Poplin GS, Roe DJ, Peate W, Harris RB, Burgess JL. The association of aerobic fitness with injuries in the fire service. Am J Epidemiol. 2013;179(2):149-55.

37. Smith DL. Firefighter fitness: improving performance and preventing injuries and fatalities. Curr Sports Med Rep. 2011;10(3):167-172. Epub 2011/05/31. https://doi.org/10.1249/JSR.0b013e31821a9fec. PubMed PMID: 21623308.

38. Zambraski EJ, Yancosek KE. Prevention and rehabilitation of musculoskeletal injuries during military operations and training. J Strength cond. 2012; 26(Suppl 2):S101-6. https://doi.org/10.1097/JSC.0b013e31825cf03b. PubMed PMID: 22728983

39. Al Attar WSA, Soomro N, Sinclair PJ, Pappas E, Sanders RH. Effect of injury prevention programs that include the Nordic hamstring exercise on hamstring injury rates in soccer players: a systematic review and metaanalysis. Sports Med. 2017;47(5):907-16. https://doi.org/10.1007/s40279-0160638-2. PubMed PMID: WOS:000401945300008

40. Neto MG, Conceicao CS, Brasileiro A, de Sousa CS, Carvalho VO, de Jesus FLA. Effects of the FIFA 11 training program on injury prevention and performance in football players: a systematic review and meta-analysis. Clin Rehabil. 2017;31(5):651-9. https://doi.org/10.1177/0269215516675906. PubMed PMID: WOS:000400198200008

41. Sewry N, Verhagen E, Lambert M, van Mechelen W, Viljoen W, Readhead C, Brown J. Exercise-based interventions for injury prevention in tackle collision ball sports: a systematic review. Sports Med. 2017;47(9):1847-57. https://doi. org/10.1007/s40279-017-0704-4. PubMed PMID: WOS:000407504200011

42. Aaltonen S, Karjalainen H, Heinonen A, Parkkari J, Kujala UM. Prevention of sports injuries-systematic review of randomized controlled trials. Arch Intern Med. 2007;167(15):1585-92. https://doi.org/10.1001/archinte.167.15. 1585. PubMed PMID: WOS:000248694500003

43. O'Brien J, Finch CF. The implementation of musculoskeletal injuryprevention exercise programmes in team ball sports: a systematic review employing the RE-AIM framework. Sports Med. 2014;44(9):1305-18. https:// doi.org/10.1007/s40279-014-0208-4. PubMed PMID: WOS:000344974100010

44. Cruz-Ferreira A, Marujo A, Folgado H, Gutierres P, Fernandes J. Exercise programs in the preventing injuries in football players: a systematic review. Rev Bras Med Esporte. 2015;21(3):236-41. https://doi.org/10.1590/151786922015210302174. PubMed PMID: WOS:000358013900015

45. Bullock SH, Jones BH, Gilchrist J, Marshall SW. Prevention of physical training-related injuries: recommendations for the military and other active populations based on expedited systematic reviews. Am J Prev Med. 2010; 38(1, Supplement):S156-S81. https://doi.org/10.1016/j.amepre.2009.10.023

46. Murphy DF, Connolly DA, Beynnon BD. Risk factors for lower extremity injury: a review of the literature. Br J Sports Med. 2003;37(1):13-29. Epub 2003/01/28. PubMed PMID: 12547739; PMCID: PMC1724594

47. United States. Health care financing administration. The international classification of diseases, 9th revision, clinical modification: ICD-9-CM. 2nd ed. Washington, D.C.?: U.S. Dept. of Health and Human Services, Public Health Service For sale by the Supt. of Docs., U.S. G.P.O.: 1980.

48. Hedegaard H, Johnson RL, Warner M, Chen LH, Annest JL. Proposed framework for presenting injury data using the international classification of diseases, tenth revision, clinical modification (ICD-10-CM) diagnosis codes. Natl Health Stat Rep. 2016;89:1-20. Epub 2016/02/02. PubMed PMID: 26828779

49. VeteranAid.org. Comparing basic training for the 5 branches of U.S. military service 2016. Available from: https://www.veteranaid.org/blog/ 2016/10/21/comparing-basic-training-5-branches-u-s-military-service/. [updated October 21, 2016].

50. Army U. Basic training frequently asked questions. Fort Benning Army.mil. Available from: www.benning.army.mil/common/faqs/BCTfaq.html. Accessed 10 Mar 2018.

51. IOM (Institute of Medicine). Finding what works in health care: standards for systematic reviews. Washington, DC: The National Academies Press; 2011.

52. Hoffmann TC, Glasziou PP, Boutron I, Milne R, Perera R, Moher D, Altman DG, Barbour V, Macdonald H, Johnston M, Lamb SE, Dixon-Woods M, McCulloch P, Wyatt JC, Chan AW, Michie S. Better reporting of interventions: template for intervention description and replication (TIDieR) checklist and guide. BMJ. 2014;348:g1687. Epub 2014/03/13. https//doi.org/10.1136/bmi.g1687. PubMed PMID: 24609605.
53. Sterne JA, Hernán MA, Reeves BC, Savović J, Berkman ND, Viswanathan M, Henry D, Altman DG, Ansari MT, Boutron I, Carpenter JR, Chan A-W, Churchill R, Deeks JJ, Hróbjartsson A, Kirkham J, Jüni P, Loke YK, Pigott TD, Ramsay CR, Regidor D, Rothstein HR, Sandhu L, Santaguida PL, Schünemann HJ, Shea B, Shrier I, Tugwell P, Turner L, Valentine JC, Waddington $\mathrm{H}$, Waters E, Wells GA, Whiting PF, Higgins JP. ROBINS-I: a tool for assessing risk of bias in non-randomised studies of interventions. BMJ. 2016;355:i4919. https://doi.org/10.1136/bmj.i4919.

54. Li B, Lingsma HF, Steyerberg EW, Lesaffre E. Logistic random effects regression models: a comparison of statistical packages for binary and ordinal outcomes. BMC Med Res Methodol. 2011;11(1):77. https://doi.org/10. 1186/1471-2288-11-77.

55. Perkins J, Wang D. A comparison of Bayesian and frequentist statistics as applied in a simple repeated measures example. J Mod Appl Stat Methods. 2004;3(1):227-33. https://doi.org/10.22237/jmasm/1083371040.

56. Huedo-Medina TB, Sanchez-Meca J, Marin-Martinez F, Botella J. Assessing heterogeneity in meta-analysis: Q statistic or 12 index? Psychol Methods. 2006; 11(2):193-206. Epub 2006/06/21. https://doi.org/10.1037/1082-989x.11.2.193. PubMed PMID: 16784338

57. Higgins JPT, Thompson SG, Deeks JJ, Altman DG. Measuring inconsistency in meta-analyses. BMJ. 2003;327(7414):557-60. PubMed PMID: PMC192859

58. Shea BJ, Reeves BC, Wells G, Thuku M, Hamel C, Moran J, Moher D, Tugwell P, Welch V, Kristjansson E, Henry DA. AMSTAR 2: a critical appraisal tool for systematic reviews that include randomised or non-randomised studies of healthcare interventions, or both. BMJ. 2017;358:j4008. Epub 2017/09/25. https://doi.org/10.1136/bmj.j4008. PubMed PMID: 28935701.

59. Atkins D, Best D, Briss PA, Eccles M, Falck-Ytter Y, Flottorp S, Guyatt GH, Harbour RT, Haugh MC, Henry D, Hill S, Jaeschke R, Leng G, Liberati A, Magrini N, Mason J, Middleton P, Mrukowicz J, O'Connell D, Oxman AD, Phillips B, Schunemann HJ, Edejer T, Varonen H, Vist GE, Williams JW Jr, Zaza S, Group GW. Grading quality of evidence and strength of recommendations. BMJ. 2004;328(7454):1490. Epub 2004/06/19. 10.1136/ bmj.328.7454.1490. PubMed PMID: 15205295; PMCID: PMC428525

\section{Ready to submit your research? Choose BMC and benefit from:}

- fast, convenient online submission

- thorough peer review by experienced researchers in your field

- rapid publication on acceptance

- support for research data, including large and complex data types

- gold Open Access which fosters wider collaboration and increased citations

- maximum visibility for your research: over $100 \mathrm{M}$ website views per year

At BMC, research is always in progress.

Learn more biomedcentral.com/submissions 